\title{
EFFECTS OF DIFFERENT PEEP LEVELS ON MESENTERIC LEUKOCYTE-ENDOTHELIAL INTERACTIONS IN RATS DURING MECHANICAL VENTILATION
}

Priscila Aikawa, ${ }^{\mathrm{III}}$ Sandra Helena Poliselli Farsky, ${ }^{\text {III }}$ Maria Aparecida de Oliveira, ${ }^{\mathrm{IV}}$
Rogério Pazetti, ${ }^{\mathrm{II}}$ Thaís Mauad, ${ }^{\mathrm{V}}$ Paulina Sannomiya, ${ }^{\text {II }}$ Naomi Kondo Nakagawa,II

doi: 10.1590/S1807-59322009000500012

Aikawa P, Farsky SHP, de Oliveira MA, Pazetti R, Mauad T, Sannomiya P, et al. Naomi Kondo Nakagawa. Effects of different peep levels on mesenteric leukocyte-endothelial interactions in rats during mechanical ventilation. Clinics. 64(5):443-50.

INTRODUCTION: Mechanical ventilation with positive end expiratory pressure (PEEP) improves oxygenation and treats acute pulmonary failure. However, increased intrathoracic pressure may cause regional blood flow alterations that may contribute to mesenteric ischemia and gastrointestinal failure. We investigated the effects of different PEEP levels on mesenteric leukocyteendothelial interactions.

METHODS: Forty-four male Wistar rats were initially anesthetized (Pentobarbital I.P. 50mg/kg) and randomly assigned to one of the following groups: 1) NAIVE (only anesthesia; $\mathrm{n}=9$ ), 2) PEEP 0 (PEEP of $0 \mathrm{cmH}_{2} \mathrm{O}, \mathrm{n}=13$ ), 3) PEEP 5 (PEEP of $5 \mathrm{cmH}_{2} \mathrm{O}$, $\mathrm{n}=12$ ), and 4) PEEP 10 (PEEP of $10 \mathrm{cmH}_{2} \mathrm{O}, \mathrm{n}=13$ ). Positive end expiratory pressure groups were tracheostomized and mechanically ventilated with a tidal volume of $10 \mathrm{~mL} / \mathrm{kg}$, respiratory rate of $70 \mathrm{rpm}$, and inspired oxygen fraction of 1 . Animals were maintained under isoflurane anesthesia. After two hours, laparotomy was performed, and leukocyte-endothelial interactions were evaluated by intravital microscopy.

RESULTS: No significant changes were observed in mean arterial blood pressure among groups during the study. Tracheal peak pressure was smaller in PEEP 5 compared with PEEP 0 and PEEP 10 groups $\left(11,15\right.$, and $16 \mathrm{cmH}_{2} \mathrm{O}$, respectively; $\left.<<0.05\right)$. After two hours of MV, there were no differences among NAIVE, PEEP 0 and PEEP 5 groups in the number of rollers $(118 \pm 9,127 \pm 14$ and $147 \pm 26$ cells/10minutes, respectively), adherent leukocytes ( $3 \pm 1,3 \pm 1$ and $4 \pm 2$ cells/100 $\mu \mathrm{m}$ venule length, respectively), and migrated leukocytes $\left(2 \pm 1,2 \pm 1\right.$ and $2 \pm 1$ cells $/ 5,000 \mu \mathrm{m}^{2}$, respectively) at the mesentery. However, the PEEP 10 group exhibited an increase in the number of rolling, adherent and migrated leukocytes $(188 \pm 15$ cells / $10 \mathrm{~min}, 8 \pm 1$ cells / $100 \mu \mathrm{m}$ and $12 \pm 1$ cells / $5,000 \mu \mathrm{m}^{2}$, respectively; $\mathrm{p}<0.05$ ).

CONCLUSIONS: High intrathoracic pressure was harmful to mesenteric microcirculation in the experimental model of rats with normal lungs and stable systemic blood pressure, a finding that may have relevance for complications related to mechanical ventilation.

KEYWORDS: Mechanical ventilation; Leukocyte-endothelial interactions; Microcirculation; Mesentery.

\footnotetext{
I Department of Physiotherapy, Communication Science \& Disorders and Occupacional Therapy, LIM 34, Faculdade de Medicina da Universidade de São Paulo - São Paulo, Brazil

II Department of Cardiopneumology, LIM-11 and LIM-61, Faculdade de Medicina da Universidade de São Paulo - São Paulo, Brazil.

III Department of Clinical and Toxicological Analyses, University of São Paulo School of Pharmacy - São Paulo/SP, Brazil.

IV Department of Pharmacology, Institute of Biomedical Sciences, University of São Paulo - Sao Paulo, Brazil.

${ }^{v}$ Department of Pathology, LIM-05, Faculdade de Medicina da Universidade de São Paulo - São Paulo, Brazil.

Email: naomikondo@uol.com.br

Tel.: 55113061.8520

Received for publication on November 20, 2008

Accepted for publication on January 28, 2009
}

\section{INTRODUCTION}

Mechanical ventilation (MV) and positive end expiratory pressure (PEEP) have been widely used to improve oxygenation and treat acute respiratory failure. However, the increased intrathoracic pressure can affect nearly every system of the body due to homeostatic interactions involving the lungs and other organs. ${ }^{1}$ These complex, dynamic interactions may contribute to several complications. Distribution of stress during cyclic tidal ventilation has been associated with macrophage, neutrophil and endothelial 
cell activation, ${ }^{2,3}$ inflammatory mediator release, ${ }^{4}$ vascular permeability alterations, ${ }^{5}$ increased adhesion molecule expression, ${ }^{6}$ and leukocyte sequestration ${ }^{3}$ in the lungs. It is also associated with a number of morbid conditions such as for instance diabetes mellitus. ${ }^{7}$

Characteristics of the splanchnic vasculature ${ }^{8}$ make the gastrointestinal tract vulnerable to adverse effects related to MV and PEEP, with a particularly pronounced risk of organ dysfunction..$^{9-13}$ Hypoperfusion appears to play a pivotal role in the pathogenesis of gastrointestinal complications in mechanically ventilated patients, the most prevalent of which are mucosal damage, hypomotility, diarrhea, mesenteric ischemia, gastrointestinal failure and sepsis. ${ }^{11,12}$ Increased intrathoracic pressure also induces diaphragmatic descent, which may play a role in increased intra-abdominal pressure during critical illness, leading to splanchnic ischemia and organ dysfunction. ${ }^{14-16}$

Several studies have focused on changes that occur at the microcirculatory level, showing that disturbances in the microcirculation may be markers of disease severity and potential predictors of the outcome of critically ill patients. ${ }^{17-19}$ In the experimental setting, intravital microscopy is a unique technique to directly observe the in vivo leukocyte-endothelial interactions. This approach has been used to investigate the mesenteric microcirculation in models of hemorrhagic shock, reperfusion and sepsis. ${ }^{20-22}$ Recently, there has been a growing interest in the effects of MV and PEEP on microcirculation. Lim and Wagner ${ }^{23}$ showed that the combination of MV and PEEP of $8 \mathrm{cmH}_{2} \mathrm{O}$ causes a significant increase in neutrophil adhesion and leukocyte recruitment in the trachea in rats. However, little is known regarding the effects of MV and PEEP on mesenteric microcirculation. The aim of the current experimental study was to investigate the effects of different PEEP levels on leukocyte-endothelial interactions at the mesentery.

\section{MATERIALS AND METHODS}

The protocol was approved by the Institutional Animal Care and Use Committee of the Heart Institute (InCor), Faculdade de Medicina da Universidade de São Paulo. The experiments were performed according to National Institutes of Health Guidelines for the use of experimental animals.

Forty-four adult male Wistar rats (200-300 g, University of Sao Paulo Medical School Laboratory Animals, Sao Paulo, Brazil) were housed in our facility for three to five days before the experiment. They were given unrestricted access to food and water. On the day of the experiment, the animals were anesthetized with pentobarbital sodium (50 mg/kg, I.P.). The right carotid artery was cannulated with a PE50 tube, and systemic arterial blood pressure was recorded on a polygraph (Polygraph MK-III-S Model, Narco Bio-Systems, TX, USA). Thereafter, animals were randomly assigned to the following experimental groups: 1) NAIVE: only anesthesia, 2) PEEP0: $\mathrm{MV}$ with $\mathrm{PEEP}=0 \mathrm{cmH}_{2} \mathrm{O}$, 3) PEEP5: $\mathrm{MV}$ with PEEP $=5 \mathrm{cmH}_{2} \mathrm{O}$ or 4) PEEP10: $\mathrm{MV}$ with $\mathrm{PEEP}=10 \mathrm{cmH}_{2} \mathrm{O}$.

Tracheostomy and Mechanical Ventilation. Animals were tracheostomized with polyethylene catheter PE45 tubes, and they were mechanically ventilated with a tidal volume of $10 \mathrm{~mL} / \mathrm{kg}$ (Harvard Ventilator, 683 Model, Harvard Rodent Apparatus, South Natick, USA) at a respiratory rate of 70 rpm and with an inspired oxygen fraction of one. Anesthesia was maintained with inhaled isoflurane (4\%) during two hours of MV.

Tracheal Peak Pressure, Blood Gas Analysis and Hematocrit. Tracheal peak pressure measurements were performed at 0 (baseline), 30, 60, 90 and 120 minutes, with a 142PC05D differential pressure transducer (Honeywell, Freeport, IL, USA) connected to a side tap in the tracheal cannula. ${ }^{24}$ Blood samples were collected from the right carotid artery for blood gas analysis and hematocrit determination. Arterial blood gases were tested by a gas analyzer (Radiometer ABL 555, Radiometer Medical, Kopenhagen, Denmark) at baseline (before MV) and after two hours of MV in all animals. Hematocrit was measured by microcapillary tube centrifugation only at baseline.

Intravital Microscopy at the Mesentery. We performed mesenteric surgical preparation as previously described. ${ }^{20,21}$ In brief, after two hours of MV, we performed a laparotomy with a midline abdominal incision, and we exposed the distal ileum and its accompanying mesentery for in vivo microscopic examination of the mesenteric microcirculation. The animals were placed in the right lateral decubitus position on a specially designed, warmed $\left(37^{\circ} \mathrm{C}\right)$ stage with a transparent platform, on which the tissue to be transilluminated was placed. The tissue was kept moist with regular applications of warm $\left(37^{\circ} \mathrm{C}\right)$ Krebs solution and covered with an impermeable membrane (Saran Wrap, Dow Chemical Co, UK) to prevent dehydration. Care was taken during handling to prevent physical damage. Mesenteric microcirculation was assessed after ten minutes of stabilization. We performed intravital microscopy in three to five microvessels after two hours of MV in each animal. Post-capillary venules with diameters ranging from 12 to $20 \mu \mathrm{m}$ were randomly selected. A CCD color camera (TKC1380U, JVC Co, Tokyo, Japan) was incorporated into a triocular microscope (Axioplan 2, Carl Zeiss Co, MünchenHallbergmoos, Germany) to facilitate observation of the enlarged image (1960x) on a computer monitor (SyncMaster 753DFX, Samsung, Manaus, Brazil). Analyses of leukocyteendothelial interactions were performed online, by using 
digital image software (KS300, Carl Zeiss Co, MünchenHallbergmoos, Germany). In addition, images were stored, enabling off-line time-delayed analysis.

Rolling Leukocytes. Rolling leukocytes were defined as white blood cells that moved at a velocity significantly slower than that of erythrocytes in a given microvessel. ${ }^{25}$ The number of rolling leukocytes was expressed in terms of the mean number of cells passing a designated line perpendicular to the venular axis every ten minutes. A given section of the vascular bed was tested only once. Three to five microvessels were tested in a single animal. Results are presented as the number of rolling leukocytes/ten minutes.

Adherent Leukocytes. A leukocyte was considered to be adherent to the venular endothelium if it remained stationary for $>30$ seconds. ${ }^{26}$ Adherent cells were counted during a tenminute period in a $100 \mu \mathrm{m}$ segment of the vessel. Three to five microvessels were selected from a single animal, and a given section of the vascular bed was tested only once. Results are presented as the number of adherent leukocytes / $100 \mu \mathrm{m}$ venule length.

Migrated Leukocytes. The number of leukocytes accumulating at the connective tissue, adjacent to the chosen post-capillary venule, was determined over a standard area of $5,000 \mu \mathrm{m} .{ }^{2,20,21}$ Three to five different fields were evaluated for each microvessel. Three to five microvessels were selected in a single animal. Results are expressed in terms of the number of migrated leukocytes $/ 5,000 \mu^{2}$.

Lung Histomorphometric Analysis. Animals were anesthetized (pentobarbital sodium, $50 \mathrm{mg} / \mathrm{kg}$ I.P.) and exsanguinated by cutting the abdominal aorta. Lungs were gently inflated $(10 \mathrm{~mL} / \mathrm{kg})$, removed and fixed with $10 \%$ formaldehyde solution in sodium phosphate buffer $0.2 \mathrm{~mol} / \mathrm{L}$ $(\mathrm{pH}$ 7.2) for 24 hours, before being dehydrated in ethanol and embedded in paraffin. Three sections $(5 \mu \mathrm{m})$ cut from the apex to the base of the right and left lungs were stained with hematoxylin-eosin (HE). Histological examinations were performed by two assistants. Briefly, by using a 100-point grid with a known area $\left(10^{4} \mu \mathrm{m}^{2}\right.$ at $\left.1000 \mathrm{x}\right)$ attached to the ocular lens of the microscope, 12-20 fields in each section (three to five sections per animal) were randomly chosen, and 1) edema volume index (volume fraction of edema/total perivascular tissue) and 2) polymorphonuclear cell density (cells $/ 10^{4} \mu \mathrm{m}^{2}$ ) were quantified within the perivascular tissue, while 3) polymorphonuclear cell density (cells / $10^{4}$ $\mu \mathrm{m}^{2}$ ) was quantified within the alveolar area. The edema volume index was assessed using the number of points in the grid colocalized with edematous tissue divided by the total number of points colocalized with the perivascular space (volume fraction). Polymorphonuclear cells were counted within either alveolar or perivascular areas. Tissue area in each field was calculated according to the number of points associated with alveolar or perivascular tissue, as a proportion of the total grid area. The density of inflammatory cells was determined from the number of positive cells in each field divided by the tissue area (cells / $10^{4} \mu \mathrm{m}^{2}$ ).

Statistical Analysis. Data are presented as means \pm standard deviations (SD). Statistical intergroup comparisons of leukocyte-endothelial interactions, lung histomorphometry, and hematocrit were performed using one-way ANOVA. Statistical comparisons of mean arterial blood pressure, tracheal pressure, and blood gas analyses among groups were performed using two-way ANOVA. Differences among groups were tested by the Tukey multiple comparisons test. A $P$ value less than 0.05 was considered significant.

\section{RESULTS}

Body weight, hematocrit, mean arterial blood pressure, respiratory parameters, and blood gas analysis. Animals presented similar values of hematocrit $(46 \pm 1)$. There were no differences in mean arterial blood pressures across groups during the two-hour study period (Figure 1). Values of arterial blood gas were similar across groups at baseline: $\mathrm{pH}$ (7.35), $\mathrm{PaO}_{2}\left(88 \pm 15 \mathrm{mmHg}\right.$ ), and $\mathrm{PaCO}_{2}(44$ $\pm 6 \mathrm{mmHg}$ ). However, as expected, after two hours of $\mathrm{MV}$, animals presented increased $\mathrm{PaO}_{2}(>300 \mathrm{mmHg}, \mathrm{p}<0.05)$ and

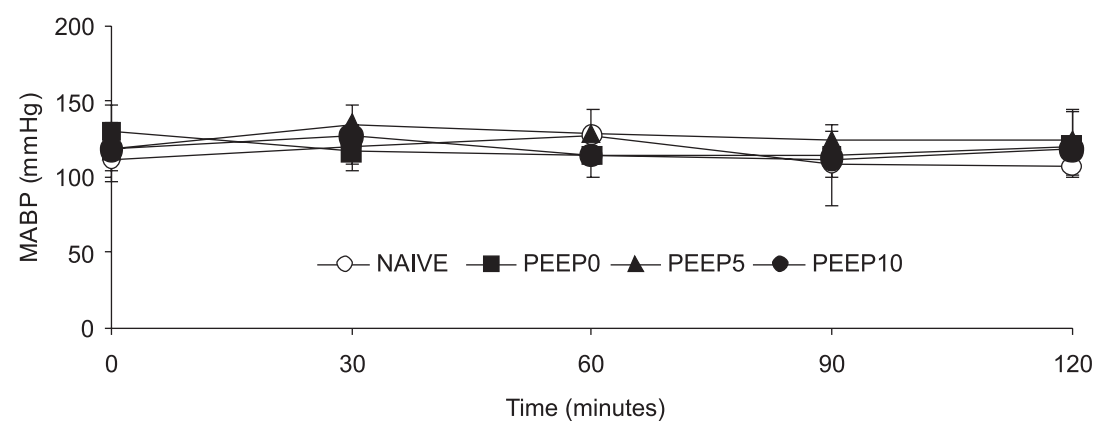

Figure 1 - Time course of mean arterial blood pressure (MABP) in NAIVE (n=9), PEEP0 (n=13), PEEP5 ( $n=12)$ and PEEP10 ( $n=13)$ groups showed no differences from baseline $(0 \mathrm{~h})$ up to 120 minutes of mechanical ventilation 
Table 1 - Mean values and standard deviations of tracheal peak pressure at the baseline, and after one and two hours of mechanical ventilation $(*, \mathrm{p}<0.05$ vs. baseline; $\dagger, \mathrm{p}<0.05$ vs. other groups at the same time points)

\begin{tabular}{lccc}
\hline Groups & Baseline & 1-hour MV & 2-hours MV \\
\hline PEEP0 & $9 \pm 1$ & $15 \pm 3^{*}$ & $16 \pm 2^{*}$ \\
PEEP5 & $9 \pm 0$ & $11 \pm 1 \dagger$ & $12 \pm 1 \dagger$ \\
PEEP10 & $10 \pm 1$ & $16 \pm 1^{*}$ & $16 \pm 1^{*}$ \\
\hline
\end{tabular}

decreased $\mathrm{PaCO}_{2}(38 \pm 2 \mathrm{mmHg}, \mathrm{p}<0.05)$, with no changes in $\mathrm{pH}$ (7.40). Tracheal peak pressure was smaller in the PEEP5 group compared with the PEEP0 and PEEP10 groups (Table 1, $\mathrm{p}<0.05$ ).

Mesenteric Leukocyte-Endothelial Interactions. Microvessel (Figure 2) diameter was similar in NAIVE, PEEP0, PEEP5 and PEEP10 groups $(13.7 \pm 2.8,11.8 \pm 3.0$, $13.8 \pm 1.6$, and $13.8 \pm 2.6 \mu \mathrm{m}$, respectively; $\mathrm{p}>0.05$ ). Few adherent and migrated leukocytes were noted within the mesentery microcirculation in animals breathing ambient air (Figure 3). There were no differences among NAIVE, PEEP0 and PEEP5 groups in the number of rolling, adherent and migrated leukocytes. However, the PEEP10 group presented an increased number of rolling, adherent and migrated leukocytes compared to the other groups $(\mathrm{p}<0.01)$.

Lung Neutrophil Infiltration and Edema by Histomorphometry. Lung tissue analysis revealed no intraalveolar hemorrhage or hyaline membranes in all groups
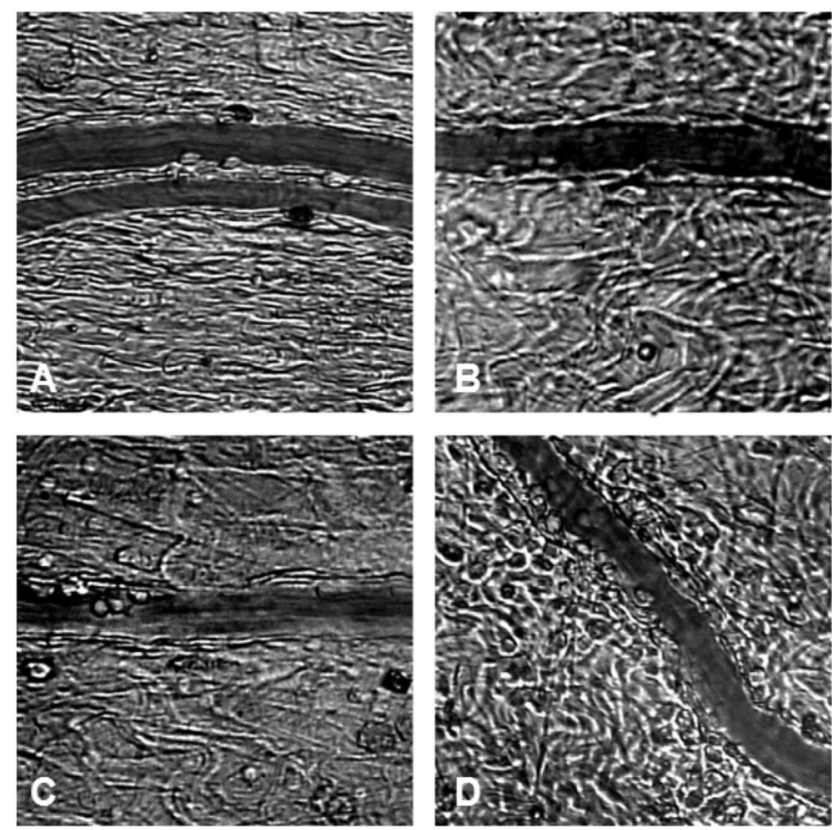

Figure 2 - Representative photomicrographs of post-capillary venules in rat mesenteric microcirculation. (A) NAIVE; (B) PEEP0; (C) PEEP5; (D) PEEP10. PEEP10 groups showed increased leukocyte migration to the perivascular tissue compared with the other groups. Original magnification x1960
(Figure 4). However, PEEP groups presented increased polymorphonuclear cell density in the parenchyma and in the perivascular tissue compared with the NAIVE group $(\mathrm{p}<0.05$,
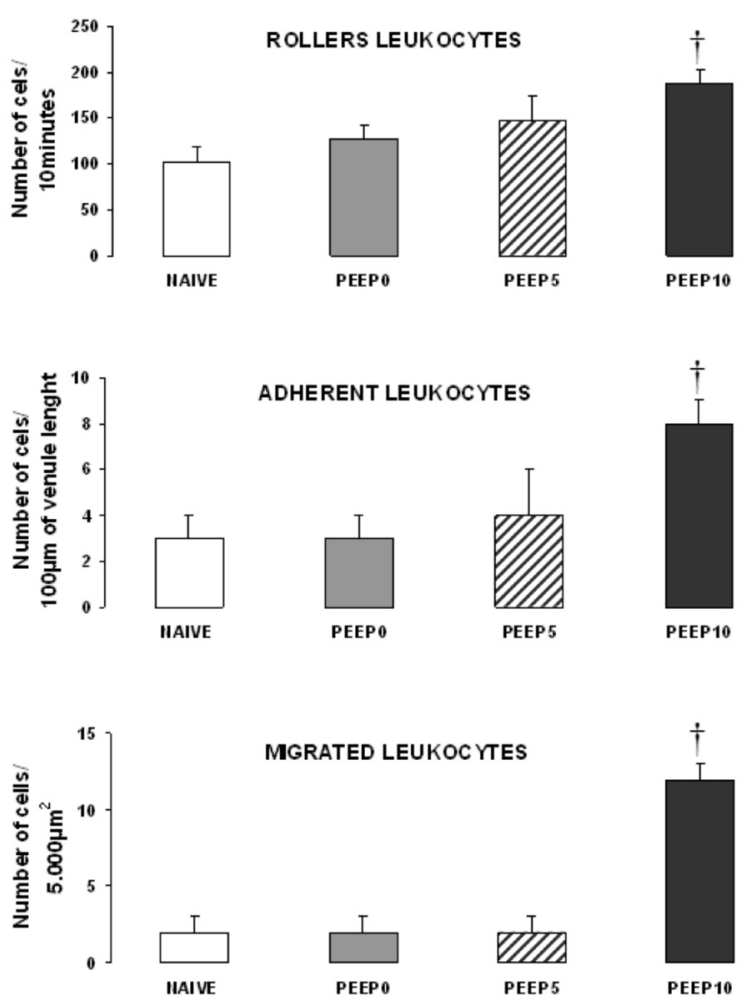

Figure 3 - Rolling (number of cells/10 minutes), adherent (number of cells $/ 100 \mu \mathrm{m}$ venule length) and migrated leukocytes (number of cells $/ 5,000$ $\left.\mu \mathrm{m}^{2}\right)$ in post-capillary venules at the mesentery (mean values \pm SD) in NAIVE $(n=3), \operatorname{PEEP0}(n=6), \operatorname{PEEP} 5(n=6)$ and PEEP10 $(n=7)$ groups. $\dagger, p<0.01$ PEEP10 vs. other groups
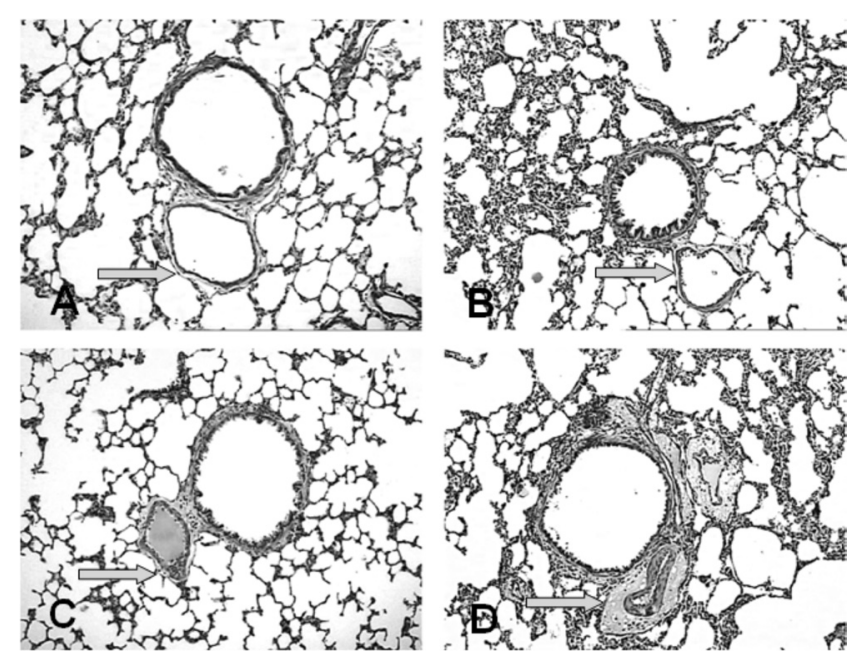

Figure 4 - Representative photomicrographs of rat lung histological sections. (A) NAIVE; (B) PEEP0; (C) PEEP5; (D) PEEP10. Presence of inflammatory cells and edema (arrows) in PEEP groups compared with the NAIVE group. Original magnification $\times 100, \mathrm{HE}$ 
Table 2 - Mean values and standard deviations of neutrophil infiltration and fluid accumulation within pulmonary microvessels and parenchyma after two hours of mechanical ventilation $\left(^{*}, \mathrm{p}<0.05\right.$ vs. NAIVE; $\dagger$, vs. others groups)

\begin{tabular}{|c|c|c|c|c|}
\hline \multirow[b]{2}{*}{ Groups } & \multirow[b]{2}{*}{$\mathrm{n}$} & \multirow{2}{*}{$\begin{array}{l}\text { Lung Parenchyma } \\
\text { Neutrophils } / 10^{4} \mu \mathrm{m}^{2}\end{array}$} & \multicolumn{2}{|c|}{ Lung Perivascular Tissue } \\
\hline & & & Edema Index & Neutrophils $/ 10^{4} \mu \mathrm{m}^{2}$ \\
\hline NAIVE & 3 & $1.22 \pm 1.19$ & $0.03 \pm 0.02$ & $0.72 \pm 0.05$ \\
\hline PEEP0 & 4 & $9.67 \pm 3.78^{*}$ & $0.24 \pm 0.03 *$ & $1.90 \pm 0.75^{*}$ \\
\hline PEEP5 & 3 & $11.49 \pm 3.36^{*}$ & $0.23 \pm 0.04 *$ & $0.72 \pm 0.47$ \\
\hline PEEP10 & 3 & $9.47 \pm 1.95^{*}$ & $0.54 \pm 0.04^{* \dagger}$ & $1.28 \pm 0.17 *$ \\
\hline
\end{tabular}

Table 2). In addition, a larger volume of perivascular edema was found in all mechanically ventilated animals compared with the NAIVE group $(\mathrm{p}<0.05)$.

\section{DISCUSSION}

The model described in the current in vivo study proved to be suitable for assessing initial injury to the mesenteric microcirculation during MV and PEEP. The use of PEEP parameters of 0 and $5 \mathrm{cmH}_{2} \mathrm{O}$ did not cause sufficient changes in leukocyte-endothelial interactions in the mesentery. However, a PEEP of $10 \mathrm{cmH}_{2} \mathrm{O}$ caused significant microcirculatory changes in the mesentery, which was evidenced by increased leukocyte rolling and adhesion in the microvasculature, as well as migration to the perivascular tissue. All mechanically ventilated animals presented leukocyte and fluid accumulation within both the pulmonary microvessels and the parenchyma.

Leukocyte-endothelial interactions are mediated by a variety of glycoproteins expressed on the surface of leukocytes and endothelial cells. The accumulation of leukocytes in inflamed tissues was found to be preceded by leukocyte rolling and adhesion to the vascular endothelium. ${ }^{27,28}$ Leukocytes roll along the walls of postcapillary venules, as mediated by the selectin family of adhesion molecules. ${ }^{27}$ Leukocytes become firmly adherent to the vascular wall on account of the interaction between ICAM-1 on endothelial cells with ${ }_{2}$ integrins on leukocytes. ${ }^{21}$ After activation, neutrophils generate and release toxic oxygen metabolites, numerous proteases, and phospholipase products, all of which may result in vasomotor changes, endothelial injury, and loss of vascular integrity. ${ }^{29}$

In rats with intact lungs, Lim and Wagner ${ }^{23}$ have studied the effects of PEEP on tracheal microcirculation, showing deleterious effects of the airway distension cause by the use of PEEP. In their study, MV was performed with a tidal volume of $6 \mathrm{~mL} / \mathrm{kg}$ and a respiratory rate of $80 \mathrm{rpm}$. Furthermore, by using PEEP of $8 \mathrm{cmH}_{2} \mathrm{O}$, the authors reported a 30-minute transitory decrease in mean arterial blood pressure, associated with decreased rolling leukocyte velocity and an increased number of rolling and adherent leukocytes in the tracheal vasculature. They concluded that PEEP of $8 \mathrm{cmH}_{2} \mathrm{O}$ is a critical level for tracheal microcirculation.

Our experimental study focused on mesenteric leukocyteendothelial interactions because the gastrointestinal tract may be under increased risk of organ dysfunction ${ }^{11,22}$ during MV and PEEP. In critically ill patients, gastrointestinal dysfunction has been associated with increased morbidity and mortality. ${ }^{11,12} \mathrm{We}$ demonstrated that the combination of a moderate tidal volume $(10 \mathrm{~mL} / \mathrm{kg})$ and high PEEP (10 $\mathrm{cmH}_{2} \mathrm{O}$ ) affected mesenteric vascular endothelium, which resulted in increased leukocyte-endothelial interactions. We speculate that these events may have been induced by gastrointestinal compression, which may have resulted in splanchnic hypoperfusion and an imbalance between oxygen supply and demand. ${ }^{14-16,30-34}$ Sequential events of hypoperfusion followed by reperfusion triggered by ventilatory strategies may be associated with acute nonocclusive mesenteric ischemia in the critical care setting. ${ }^{35}$

We also observed leukocyte and fluid accumulation within pulmonary microvessels and parenchyma in all mechanically ventilated animals. Eosinophils were absent. We speculate that the histologic lung alterations observed in all mechanically ventilated rats may be a consequence of tracheal intubation, exposure to hyperoxia, and alveolar overdistension during mechanical tidal cycling, all of which may be associated with vascular damage and increased polymorphonuclear cell accumulation in lungs. ${ }^{2-6,36,37}$

This study has limitations. Animals submitted to MV and PEEP were ventilated with a $100 \%$ inspired oxygen fraction, although subsequent hyperoxia may have influenced lung results. However, this protocol was used to avoid any possibility of hypoxia. In fact, hypoxia has been associated with rapid increases in vascular permeability and in leukocyte adherence and migration into the extravascular space of the mesenteric microcirculation in rats. ${ }^{38}$ Secondly, one may argue that in clinical practice, high PEEP levels have been widely used only in patients with acute lung injury, in which the cardiovascular effects of increased intrathoracic pressure are potentially reduced. ${ }^{39}$ However, patients with normal 
lungs may require MV during deep sedation or anesthesia in the surgical, emergency, and intensive care units. Ventilatory strategies using a moderate tidal volume of $10 \mathrm{~mL} / \mathrm{kg}$ and PEEP levels from zero up to $10 \mathrm{cmH}_{2} \mathrm{O}$ have been used with surgical patients. ${ }^{9,40}$ Thirdly, PEEP in the setting of relatively normal lungs and without fluid administration is very likely to reduce cardiac output - we did not measure cardiac output or mesenteric blood flow. However, fluid administration or inotropic agents may have affected microcirculation. Besides, we identified significant alterations in mesenteric leukocyte-endothelial interactions despite the unchanged mean arterial blood pressure among groups. Finally, although we did not demonstrate the mechanism involved in this inflammatory response at the mesentery that caused increased intrathoracic pressure, it is reasonable to hypothesize that the combination of a number of mechanical forces, such as alveoli overdistention, lung stretch, and compressive stress on the gastrointestinal organs may have resulted in mesenteric hypoperfusion and inflammation.

In conclusion, the current animal study shows that the association of moderate tidal volume and high PEEP may be harmful to mesenteric microcirculation in the setting of normal lungs and stable systemic blood pressure. This finding may have relevance in understanding the development of complications related to MV.

\section{ACKNOWLEDGMENTS}

The authors would like to thank Dr. Carmem Valente Barbas, Dr. Daniel de Backer and Dr. Luciano Gattinoni for outstanding discussion in the poster session of International Symposium on Intensive Care and Emergency Medicine for Latin America, and Julia Fukushima for cooperation in the statistical analysis. Photomicrographs were taken by the Museum of Pathology, Faculdade de Medicina da Universidade de São Paulo. The platform for intravital microscopic study of the rat mesentery was developed by Dr. Naomi Kondo Nakagawa, Simão Bacht, and Dr. Idágene Cestari, and built by the Bioengeering Division of the Heart Institute (InCor), Faculdade de Medicina da Universidade de São Paulo. This work was supported by grant of PRONEX and FAPESP (proc. 07/51605-9).

\section{REFERENCES}

1. Beyer J, Beckenlechner P, Messmer K. The influence of PEEP ventilation on organ blood flow and peripheral oxygen delivery. Intensive Care Med. 1982;8:75-80.

2. Frank JA, Wray CM, McAuley DF, Schwendener DF, Matthay R, Michael A. Alveolar macrophages contribute to alveolar barrier dysfunction in ventilator-induced lung injury. Am J Physiol Lung Cell Mol Physiol. 2006;291:L1191-8.
3. Zhang H, Downey GP, Suter PM, Slutsky AS, Ranieri VM. Conventional mechanical ventilation is associated with bronchoalveolar lavageinduced activation of polymorphonuclear leukocytes. a possible mechanism to explain the systemic consequences of ventilator-induced lung injury in patients with ARDS. Anesthesiology. 2002;97:1426-33.

4. Held HD, Boettcher S, Hamann L, Uhlig S. Ventilation-induced chemokine and cytokyne release is associated with activation of nuclear factor-B and is blocked by steroids. Am J Respir Crit Care Med. 2001;163:711-6. 
5. Dries DJ, Adams AB, Marini JJ. Time course of physiologic variables in response to ventilator-induced lung injury. Respiratory Care. 2007;52:31-7.

6. Miyao N, Suzuki Y, Takeshita K, Kudo H, Ishii M, Hiraoka R, et al. Various adhesion molecules impair microvascular leukocyte kinetics in ventilator-induced lung injury. Am J Physiol Lung Cell Mol Physiol. 2006;290:L1059-68.

7. Alba-Loureiro TC, Munhoz CD, Martins JO, Cerchiaro GA, Scavone $\mathrm{C}$, Curi R, et al. Neutrophil function and metabolism in individuals with diabetes mellitus. Braz J Med Biol Res. 2007;40:1037-44.

8. Ceppa EP, Fush KC, Bulkley GB. Mesenteric hemodynamic response to circulatory shock. Curr Opin Crit Care. 2003;9:127-32.

9. Aneman A, Pontén J, Fändriks L, Olbe L, Dalenbäck J, Nitescu P, et al. Hemodynamic, sympathetic and angiothensin II responses to PEEP ventilation before and during administration of isoflurane. Act Anaesthesiol Scand. 1997;41:41-8.

10. Love R, Choe E, Lippton H, Flint L, Steinberg S. Positive end-expiratory pressure decreases mesenteric blood flow despite normalization of cardiac output. J Trauma. 1995;39:195-9.

11. Mutlu GM, Mutlu EA, Factor P. GI complications in patients receiving mechanical ventilation. Chest. 2001;119:1222-41.

12. Cook D, Heyland D, Griffith L, Cook R, Marshall J, Pagliarello J, et al. Risk factors for clinically important upper gastrointestinal bleeding in patients requiring mechanical ventilation. Canadian Critical Care Trials Group. Crit Care Med. 1999;27:2812-7.

13. Silva AM, Signori LU, Plentz RD, Moreno Jr H, Barros E, Belló-Klein A, et al. Hemodialysis improves endothelial venous function in end-stage renal disease. Braz J Med Biol Res. 2008;41:482-8.

14. Malbrain ML, Chiumello D, Pelosi P, Bihari D, Innes R, Ranieri VM, et al. Incidence and prognosis of intraabdominal hypertension in a mixed population of critically ill patients. a multiple-center epidemiological study. Crit Care Med. 2005; 33:315-22.

15. Diebel LN, Dulchavsky AS, Wilson RF. Effect of increased intraabdominal pressure on mesenteric and intestinal mucosal blood flow. J Trauma. 1992; 33:45-9.

16. Caldwell CB, Ricotta JJ. Changes in visceral blood flow with elevated intraabdominal pressure. J Surg Res. 1987;43:14-20.

17. De Backer D, Creteur J, Preiser JC, Dubois MJ, Vincent JL. Microvascular blood flow is altered in patients with sepsis. Am J Respir Crit Care Med. 2002; 166:98-104.

18. Sakr Y, Dubois MJ, De Backer D, Creteur J, Vincent JL. Persistent microcirculatory alterations are associated with organ failure and death in patients with septic shock. Crit Care Med. 2004;32:1825-31.

19. Trzeciak S, Dellinger RP, Parrillo JE, Guglielmi M, Bajaj J, Abate NL, et al. Early microcirculatory perfusion derangements in patients with severe sepsis and septic shock: relationship to hemodynamics, oxygen transport, and survival. Ann Emerg Med. 2007;49:88-98.

20. Nakagawa NK, Jukemura J, Aikawa P, Nogueira RA, Poli-de-Figueiredo LF, Sannomiya P. In vivo observation of mesenteric leukocyteendothelial interactions after cecal ligation/puncture and surgical source Naive. Clinics. 2007;62:321-6.
21. Nakagawa NK, Nogueira RA, Correia CJ, Shiwa SR, Costa Cruz JW, Poli de Figueiredo LF, et al. Leukocyte-endothelium interactions after hemorrhagic shock/reperfusion and cecal ligation/puncture. an intravital microscopic study in rat mesentery. Shock. 2006;26:180-6.

22. Zakaria el R, Garrison RN, Kawabe T, Harris PD. Role of neutrophils on shock/resuscitation-mediated intestinal arteriolar derangements. Shock. 2004; $21: 248-53$

23. Lim LHK, Wagner EM. Airway distension promotes leukocyte recruitment in rat tracheal circulation. Am J Respir Crit Care Med. 2003;168:1068-74

24. Prado CM, Leick-Maldonado EA, Yano L, Leme AS, Capelozzi VL, Martins MA, et al. Effects of nitric oxide synthase in chronic allergic airway inflammation and remodeling. Am J Respir Cell Mol Biol. 2006;35:457-65.

25. Xie X, Hedqvit P, Lindbom L. Influence of local haemodynamics on leukocyte rolling and chemoattractant-induced firm adhesion in microvessels of the rat mesentery. Acta Physiol Scand. 1999; 165:2518.

26. Kubes P, Heit B, Van Marle G, Johnston JB, Knight D, Khan A, et al. In vivo impairment of neutrophil recruitment during lentivirus infection. J Immunology. 2003; 171:4801-8.

27. Kishimoto TK, Rothlein R. Integrins, ICAMs, and selectins. role and regulation of adhesion molecules in neutrophil recruitment to inflammatory sites. Adv Pharmacol. 1994;25:117-69.

28. Madorin WS, Martin CM, Sibbald WJ. Dopexamine attenuates flow motion in ileal mucosal arterioles in normotensive sepsis. Crit Care Med. 1999;27:394-400

29. Wichterman KA, Baue AE, Chaudry IH. Sepsis and septic shock: a review of laboratory models and a proposal. J Surg Res. 1980;29:189201

30. Spirit MJ, Guth PH, Randall G, Leung FW. Gastroduodenal perfusion and mortality in mechanical ventilation-dependent patients with systemic inflammatory response syndrome. Digest Dis Sciences. 2004;49:90613.

31. Brienza N, Revelly JP, Ayuse T, Robotham JL. Effects of PEEP on liver arterial and venous blood flow. Am J Respir Crit Care Med. $1995 ; 152: 504-10$

32. Fournell A, Scheeren TWL, Schwarte LA. PEEP decreases oxygenation of the intestinal mucosa despite normalization of cardiac output. Adv Exp Med Biol. 1998;454:435-40.

33. Schwarte LA, Scheeren TW, Lorenz C, De Bruyne F, Fournell A Moderate increase in intraabdominal pressure attenuates gastric mucosal oxygen saturation in patients undergoing laparoscopy. Anesthesiology. 2004;100:1081-7.

34. Fournell A, Schwarte LA, Kindgen-Milles D, Müller E, Scheeren TW. Assessment of microvascular oxygen saturation in gastric mucosa in volunteers breathing continuous positive airway pressure. Crit Care Med. 2003;31:1705-10

35. Bassiouny HS. Nonocclusive mesenteric ischemia. Surg Clin North Am 1997; 77:319-326.

36. Nishio K, Suzuki Y, Aoki T, Suzuki K, Miyata A, Sato N, et al. Differential contribution of various adhesion molecules to leukocyte kinetics in pulmonary microvessels of hyperoxia-exposed rat lungs. Am J Respir Crit Care Med. 1998;157:599-609. 
37. Sinclair SE, Altemeier WA, Matute-Bello G, Chi EY. Augmented lung injury due to interaction between hyperoxia and mechanical ventilation. Crit Care Med. 2004;32:2496-501.

38. Wood JG, Johnson JS, Mattioli LF, Gonzalez NC. Systemic hypoxia increases leukocyte emigration and vascular permeability in conscious rats. J Appl Physiol. 2000;89:1561-8.
39. Boker A, Haberman CJ, Girling L, Guzman RP, Louridas G, Tanner $\mathrm{JR}$, et al. Variable ventilation improves perioperative lung function in patients undergoing abdominal aortic aneurysmectomy. Anesthesiology. 2004;100:608-16.

40. Krenn CG, Krafft P, Schaefer B, Pokorny H, Schneider B, Pinsky MR, et al. Effects of positive end-expiratory pressure on hemodynamics and indocyanine green kinetics in patients after orthotopic liver transplantation. Crit Care Med. 2000;28:1760-5. 